The research program of the Center for Economic studies (CES) produces a wide range of theoretical and empirical economic analyses that serve to improve the statistical programs of the U.S. Bureau of the Census. Many of these analyses take the form of CES research papers. The papers are intended to make the results of CES research available to economists and other interested parties in order to encourage discussion and obtain suggestions for revision before publication. The papers are unofficial and have not undergone the review accorded official Census Bureau publications. The opinions and conclusions expressed in the papers are those of the authors and do not necessarily represent those of the U.S. Bureau of the Census. Republication in whole or part must be cleared with the authors.

\title{
THE MANUFACTURING PLANT OWNERSHIP CHANGE DATABASE: ITS CONSTRUCTION AND USEFULNESS
}

\author{
Sang V. Nguyen \\ Center for Economic Studies \\ U. S. Bureau of the Census \\ E-mail: snguyen@census.gov \\ CES98-16 September 1998
}

This paper was presented at the 1998 ASA Annual Meetings in Dallas, Texas, August 13, 1998. The author would like to thank Tim Dunne, Kathy Friedman, John Haltiwanger, Ron Jarmin, C. Z. Krizan, Bob McGuckin, Arnie Reznek and Mary Streitwieser for their comments. Any opinions, findings or conclusions expressed here are those of the author and do not necessarily reflect the views of the U.S. Bureau of the Census. 
All papers are screened to ensure that they do not disclose confidential information. Persons who wish to obtain a copy of the paper, submit comments about the paper, or obtain general information about the series should contact Sang V. Nguyen, Editor, Discussion Papers, Center for Economic Studies, Washington Plaza II, Room 211, Bureau of the Census, Washington, DC 20233-6101, (301-457-1882) or INTERNET address snguyendinfo.census.gov. 


\begin{abstract}
The Center for Economic Studies, U. S. Bureau of the Census, has constructed the "Manufacturing Plant Ownership Change Database" (OCD)using plant-level data taken from the Census Bureau's Longitudinal Research Database (LRD). The OCD contains data on all manufacturing establishments that have experienced ownership change at least once during the period 1963-1992. This is a unique data set which, together with the LRD, can be used to conduct a variety of economic studies that were not possible before. This paper describes how the OCD was constructed and discusses the usefulness of these data for economic research.
\end{abstract}

Keywords: manufacturing; plant-level data; ownership change; data matching.

\title{
I. Introduction
}

The purpose of this paper is to document the construction of the Manufacturing Plant Ownership

Change Database (OCD) and to discuss its usefulness in economic research. This database is constructed with plant-level data taken from the U.S. Bureau of the Census' Longitudinal Research Database (LRD) . The LRD is composed of the data for U.S. manufacturing collected in the last 7 
Censuses of Manufactures (CM, 1963, 67, 72, 77, 82, 87 and 92) and in the last 16 Annual Surveys of Manufactures (ASM) beginning with the 1973 survey.

The OCD contains data on nine vatiables (listed in section III) for all manufacturing plants that changed their firm identification numbers at least once during the period 1963-92. Because each plant in the OCD and LRD is assigned a unique permanent plant number (PPN), researchers can use this number to merge the OCD with the LRD. In this way, data on many other variables available in the LRD -describing economic activities of the plants that changed owners as well as those that did not experience any ownership change (the control group) — may be obtained for research.

The OCD is constructed for several important reasons. First, ownership changes -- through mergers and acquisitions -- have long been an important activity in the U.S. economy. During the last decade, for example, the aggregate assets transferred through acquisitions and corporate takeovers have averaged more than $\$ 230$ billion a year (see Mueller, 1993). This volume of transactions has motivated a large, growing body of both theoretical and empirical studies on acquisitions and corporate takeovers. Yet, the causes and consequences of this important economic activity are not well understood. The empirical findings from the many studies based on aggregate data are controversial. ${ }^{1}$ Thus, new microdata are imperative to arrive at more definitive research results on this important topic.

Second, while previous studies have generated conflicting results, they have shared a common method for evaluating the effects of mergers and acquisitions. That is, in most cases, researchers compare the firm's performance (e.g., sales, employment, profit, productivity, etc.) before and after mergers. A problem with this methodology is that it fails to take into account the specific changes in the

${ }^{1}$ For example, Ravenscraft and Scherer (1987) found no evidence of firms' improved performance in the post-takeover period. Mueller (1985 and 1993) reached the same conclusion. In contrast, Kaplan (1989) and Healy, Palepu and Ruback (1990) found that firms improved performance (sales, income, asset productivity, etc.). For more details on these conflicting results, see Mueller (1993). 
performance of the different components (i.e, individual plants) of multi-unit firms that are the real consequences of mergers. In his review article, "Mergers: Theory and Evidence," Mueller (1993) points out that: "Any real consequences of a merger must come about through changes in the development of one or both joining units that can be attributed to the merger in the following years."

This suggests that simply comparing the performance of the whole firm before and after a merger is not an appropriate way to evaluate its effect on the merging firm. Indeed, because mergers and acquisitions are part of a strategy to realign the resources and operations within the firm, then research results must identify precisely where changes took place within the firm in the years following the transaction. These changes include the change in the mix of plants by the acquiring firm. That is, before merging the acquiring firm owns a set of plants, some of which will be closed, some will be sold, and others will be retained so that after merging, the structure of the firm may be much different from before. Thus using firm-level data to assess the effects of merger on multi-establishment firms could lead to misleading results ${ }^{2}$. With plant-level data in the OCD, researchers can take a close look at the performance of each component of the firm, before and after merger, and more accurately evaluate the economic impact of mergers and acquisitions on the merging firms.

Empirically, McGuckin and Nguyen (1998) used both plant and firm level data for the U.S. manufacturing food industry (SIC 20) taken from the LRD-OCD to study the effects of mergers and acquisitions. They found that firm-level data are too aggregative to capture the composition effects of acquisitions on the performance of multi-unit acquiring firms.

${ }^{2}$ For example, if after merger the productivity of newly acquired plants declines or remains the same, but the productivity of the firm as a whole increases substantially due to its highly productive, newly built plants. This shows that using firm-level data to compare the firm's productivity before and after a merger would lead the researcher to the erroneous conclusion that the merger improved productivity in the acquired plants. 
Moreover, because the data are plant-level the OCD also allows researchers to investigate the economic impact of certain transactions that could not previously be evaluated with firm-level data. These transactions include partial acquisitions, divestitures and asset sales which involve only one or several plants of a large multi-unit firm, or prerhaps, only assets (e.g., buildings). Also, with industry codes at the plant-level available in the OCD, researchers can determine the exact type of acquisition such as related (horizontal or vertical) or unrelated (conglomerate) mergers (see McGuckin, Nguyen and Andrews, 1991).

Finally, most previous studies use financial data to study mergers and acquisitions and then draw conclusions about the economic efficiency (or inefficiency) of these transactions. Jensen (1988), for example, used financial data in his study and concluded that corporate takeovers generate substantial gains in economic efficiency. One could argue, however, that financial gains to the shareholders of the companies involved in these transactions are not necessarily the desirable social gains or economic efficiency. Most economists agree that productivity is the best available measure of economic efficiency and it can only be evaluated with data on "real" variables such as output and inputs in production rather than with financial data. The OCD provide data on such "real" variables.

The next section delineates the concept and measurement of ownership. Section III describes the data and method of identifying ownership changes. Section IV presents the matching results. Section V briefly reviews some lessons learned from the OCD data. The last section concludes with a discussion of the strengths and weaknesses of the database.

\section{Ownership: Concept and Measurement ${ }^{3}$}

Ownership refers to the person(s) who owns and controls particular resources in the economy.

\footnotetext{
${ }^{3}$ This section draws upon materials in McGuckin, Nguyen and Reznek (1998, forthcoming).
} 
If owners have a complete control and make all the decisions about the uses of these scarce resources, then ownership changes will significantly affect the way the resources are used. Thus, ownership and ownership changes are important aspects of economic growth and have important policy implications. For example, antitrust authorities are concerned with the effects of ownership change on output and pricing decisions. $^{4}$

It should be noted that the ownership concept used in the OCD does not exactly match those used for policy purposes. The key issue for policy is "control". However, measuring "control" is particularly difficult for corporations where the extent of "ownership" is determined by the proportion of the ownership shares held by an owner and by the legal rules for exercising those shares. Usually, if a firm acquires more than 50 percent of the shares of another company, it can be considered as having the ability to control that company.

The issue of who controls corporate assets has a long history. It was raised over 50 years ago by Berle and Means (1932) and is the subject of a large literature. Note that in some contexts, criteria other than 50 percent ownership are used to approximate a level of ownership at which control is exerted. For example, for many securities transactions, a company is considered to be under the control of another if more than 10 percent of its stock is obtained by one investor. The ownership concepts in the LRD reflect the LRD's roots in the Census Bureau's Standard Statistical Establishment List (SSEL). ${ }^{5}$ The SSEL is

${ }^{4}$ Also, the Securities and Exchange Commission protects minority shareholders' (owners') rights and protects the public against securities fraud. These issues often became important when ownership shifts from one person or group to another. The Department of Labor is also concerned with issues involving worker rights and working conditions that can change when ownership changes.

${ }^{5}$ The SSEL is described in U.S. Bureau of the Census (1979), and its role in the Census Bureau's manufacturing establishment surveys is described in Cole, Petrik, and Struble (1995). 
used as a sampling frame for most Census Bureau surveys of businesses with one or more employees ${ }^{6}$. The SSEL contains current information on ownership, address, industry classification, employment, payroll, and operational status of each establishment. It also includes limited historical information. The SSEL is based on administrative information maintained in Internal Revenue Service (IRS), Social Security Administration (SSA), and (since 1990) Bureau of Labor Statistics (BLS) records. To facilitate the tracking of ownership at the plant level for the multi-unit companies in the SSEL, the Census Bureau collects information from all multi-unit companies both in the Economic Census (taken every five years) and, in non-census year, from a sample of companies in the Company Organization Survey (COS). Moreover, ownership information on multi-unit companies is often obtained from other ongoing Census Bureau surveys.

For the Census Bureau, a company (Company A) owns another company (Company B) if either of two basic criteria are met: (1) Company A owns more than 50 percent of the voting stock of Company B, or (2) Company A has the power to direct the management and policies of Company B. Census Bureau data collection forms ask respondents whether they own or are owned by other companies. If the answer is a yes, the forms request the name, address, and employer identification (EI) number of the owned or owning companies. Each business with paid employees is required to obtain a 9-digit EI number from the IRS.

Before proceeding, it is important to make a clear distinction between the firm ID and EI numbers in the LRD. The firm ID is a ten-digit number assigned to each plant by the Census Bureau. This number provides information on organizational status and company affiliation of the plant. A "multi-unit" establishment ID number consists of a six-digit company number (called the "alpha" number, which is

${ }^{6}$ The SSEL currently covers the following economic sectors: Agriculture, Mining, Manufacturing, Transportation and Communication, Wholesale, Retail, Finance, Insurance, and Real Estate, Services, and Public Administration. 
common to all plants owned by the same company), followed by a 4-digit number specific to the reporting plant. In contrast, the EIN is a 9-digit number given to a firm by the IRS. To facilitate companies' tax reporting, the IRS can and does assign multiple IENs to a multi-unit firm that has plants in different locations. Thus, for a plant owned by a multi-unit firm, its ID number is not the same as its EIN. It is the ID number, not the EIN, that represents ownership.

For a single-unit plant, its ID number is composed of a leading zero followed by a 9-digit EI number. Thus, the firm ID for a single-unit plant is the same as its EI number except that the ID is tendigit number beginning with a zero. This leading zero indicates that the plant is owned by a single-unit firm. Thus, to identify ownership and ownership changes we use ID numbers rather than EI numbers.

In the LRD, the ID number of a particular plant can and does change over time. An ID change often indicates an ownership change; but, it can indicate other things as well (see below). The following describes the data and the process we used to identify ownership changes and separate them from other types of ID changes.

\section{The Data and Method for Identifying Ownership Change}

\section{A. The Data}

\section{Contents of the $O C D$}

The OCD contains data for all establishments that changed their firm IDs at least once during the period 1963-92. There are 86,700 such establishments in the database. Because one can use PPNs and IDs to merge the OCD with LRD to obtain data on many variables available in the LRD, the OCD is designed to contains only the following nine variables: ${ }^{7}$

\footnotetext{
${ }^{7}$ See the appendix for a detailel description of these variables.
} 
(1) BUYID: ID number of the buying (acquiring) firm.

(2) CC: Coverage code.

(3) ID: Firm identification number.

(4) IND: 4-digit SIC industry code.

(5) PPN: Permanent plant number.

(6) SELLID: ID number of the selling (acquired) firm.

(7) STATUS: This variable indicates whether an ID change is an ownership change.

(8) TE: Total employment (number of employees).

(9) TVS: Total value of shipment.

Using PPN and ID numbers, researchers can merge the OCD with the LRD to obtain data on many other variables for their research.

\section{Data sources}

The data used to construct the OCD data file are taken from the LRD. At present, the LRD consists of seven CMs for the years 1963, 1967, 1972, 1977, 1982, 1987 and 1992 and 16 ASMs for the years between census years, starting in 1973. The LRD contains data on output, inputs, and production costs of individual U.S. manufacturing establishments. The output data include total value of shipments, value added and related variables such as inventories of work-in-process and finished goods. Data on inputs include information on capital, labor, energy, materials, and selected purchased services. The employment data include total employment, production workers, non-production workers, production worked hours as well as salaries and wages. ${ }^{8}$

An important feature of the LRD is its plant industry classification and identification information, including firm affiliation, location, products and industries, and various status codes which identify, among

\footnotetext{
${ }^{8}$ For a more detailed description of the CM, ASM and LRD, see McGuckin and Pascoe (1988).
} 
other things, birth, death, and ownership changes. These identifying codes are used in developing both the longitudinal plant linkages and ownership linkages among plants.

\section{Assessing the Data}

Plant and company level data in the LRD and OCD are collected by the Census Bureau under the authority of Title 13 of the United States Code. To protect confidentiality of the data, Title 13 and the rules and regulations of the Census Bureau prohibit the release of micro data that could be used to identify or closely approximate the data on a plant or a company. Thus, only sworn Census employees have direct access to these microdata.

While the Census Bureau considers confidentiality protection a binding constraint, it provides as much public information as possible within this constraint. One of the mission of the Census Bureau's Center for Economic Studies (CES) is to make economic microdata, collected by the Census Bureau, available to economic policy makers and researchers in the forms conducive to research and analysis. Therefore, CES maintains and provides access to these microdata.

In order for a non-Census researcher to gain access to microdata at the CES or its Research Data Centers (RDC), they would have to become a special sworn employee (SSE) ${ }^{9}$ It is important to emphasize that while SSEs can access directly to CES' microdata, perform analysis on the data, and include research results in papers and reports, they cannot remove any portion of these data files from CES or its RDCs. In addition, the CES will review all materials produced by SSEs for disclosure of sensitive information. In general, no information that could be used to identify or to approximate the level

${ }^{9}$ Most SSEs working with CES or its RDCs are employees of Federal agencies engaging in statistical work and related activities or individuals affiliated with universities, research, or researchrelated organizations when such individuals can provide expert advice or assistance on CES projects. For information on access to microdata at the CES, contact Mary L. Streitwieser, Center for Economic Studies, U.S. Bureau of the Census, Washington D.C., 20233, (301) 457-1837, e-mail: mstreitw@ces.census.gov. 
of activity of a plant or a company can be included in papers and reports.

\section{B. Method of Identifying Ownership Change}

The following three-step procedure is used to target ownership changes:

(1) Using PPN and firm ID numbers to identify plants that changed firm IDs between two census years.

(2) Within this set of plants, using CC codes to identify directly reasons for ID changes (e.g., ownership change, a "multi-unit" plant becomes a single-unit firm, reorganization, etc.).

(3) From the remaining plants, identifying further ownership changes indirectly by matching the firm IDs of acquired firms and acquiring firms.

These three steps are described in tables 1, 2 and 3 where PPNs, IDs and changes in the IDs are arbitrarily made up for demonstration purposes. Step (1) matches plants' PPNs over time and records the change in the firm ID number of each establishment in the period under study as illustrated in table 1.

Note that a change in firm ID does not necessarily mean a true ownership change. As shown in table 2, an ID change can be any of the following:

(1) Acquisition: The establishment was sold to another firm -- a true ownership change (mergers and acquisitions).

(2) Company Structure Change: A multi-unit firm ( a firm that owns more than one plant) closed or sold all of its plants but one and became a single-unit ( a firm with only one plant); or a single-unit firm became a multi-unit firm by opening new plants or acquiring existing plants.

(Note that the ID variable in the LRD for each plant of a multi-unit firm incorporates a code for the firm to which the plant belongs.)

(3) Reorganization: A multi-unit undergoes a legal reorganization (e.g., partnership to 
corporation) that spurs a firm ID change without a change in actual ownership.

(4) Split: New operation resulting from the splitting of a previously combined report.

(5) Reactivation: Previously idle establishment that resumed activity under a new firm ID.

(6) Reclassification: Establishment previously classified as non-manufacturing that has now been reclassified as manufacturing as a result of census processing.

(7) Duplication: The establisment is a duplicate of another establishment.

(8) Combination: New operation resulting from combining at least two previously separate reports (i.e., the data of this establishment are now being included with other establishments data on a new combined report).

(9) Errors -- erroneous ID changes can occur.

To identify true ownership changes (mergers and acquisitions) -- step (2) -- it is necessarily to use other information available in the LRD in addition to the ID variable. The main additional information is in the census CC codes assigned to establishments in the CM or ASM. The CC codes are two-digit numbers that indicate the status of the establishment in the survey. For example, a value of a CC code equal to 18 indicates that the establishment was sold to another company. ${ }^{10}$ Table 2 demonstrates this step.

Ideally, all new firm ID and CC codes would be recorded during the years that establishments change status (including ownership), so that it would be easy to identify ownership changes. In practice, this does not always happen. Except for a set of large ASM establishments, neither changes in ID nor proper CC codes are systematically recorded during the years of status change. In many cases, particularly for small establishments, a change in the firm ID of a plant appears one or more years before

${ }^{10}$ For a complete list of CC codes, see the LRD documentation (U.S. Bureau of the Census, Center for Economic Studies, 1992, a revised version of this documentation is forthcoming). 
a proper CC code is assigned. The reverse is also possible: the CC code can indicate an ownership change before the ID changes. To address these issues, for the years when ASM data were available, we examined $\mathrm{CC}$ codes in the years before and after the ID change. However, this procedure leaves two unresolved problems. First, in non-Census years, not all plants are in the survey sample and, in particular, when the ASM panel changes (in years ending in 4 and 9), the set of non-certainty cases (the smaller plants) turns over completely. Secondly, for a number of establishments, proper CC codes are not assigned at all. This is demonstrated by our example in Table 2 where the hypothetical plants 1,5 and 11 have $\mathrm{CC}$ codes with missing values. Nevertheless, using CC codes allows identification of a large portion of the establishments that have ID changes due to true ownership changes. ASM data also help to identify true types of ID change.

Finally, in step 3 it is necessarily to bring together initial and ending firm IDs for all plants that were owned by the firm in question. For example, assume that the LRD shows that plant A belonged to firm X in 1977 and to firm Y in 1982, but the 1982 CC code for plant A does not show this as an ownership change. But assume, also, that firm $\mathrm{Y}$ acquired at least one other plant from firm $\mathrm{X}$ between 1977 and 1982, as confirmed by the CC codes. In this case, it seems likely that firm Y bought plant A as well, and we code plant A accordingly. Consider table 3, we see that in 1982, firm 444444 owned 4 plants, all of which were owned by other firms in 1977. Using CC codes we find that plant 4 was acquired from firm 333333 and plant 9 was acquired from firm 777777. Plants 1 and 5 were owned by firm 333333 and single-unit firm 0900000000, respectively. While these two plants have CC codes with missing values, we code them as having ownership change because firm 444444 did acquire plants 4 and 9 from firms 333333 and 777777 as confirmed by the CC codes.

\section{The Matching Results: 1963-1992}


Table 4 and Charts 1-3 show the results of ownership changes identified using the above procedure. In the table and charts, I classify plants into 3 categories:

(1) "Acquired": indicates that the plant was acquired by another firm (true ownership change).

(2) "Other": indicates that the plant changed its firm ID for a known reason other than being acquired (such as a single-unit firm becomes a multi-unit firm, or ID changes due to legal reorganization, errors, etc.).

(3) "Unknown": indicates an ID change for an unknown reason.

From column (2) of table 4 and chart 1, we see that the percentage of plants identified as having true ownership change is rather low in the earlier periods. In 1963-67, among 7,242 establishments having ID changes, only 3,694 (51.06 percent) were identified as being "acquired". We were not able to determine the reasons for firm ID change for 3,336 establishments (46.06 percent). In 1967-72, there are more establishments experiencing firm ID changes. However, again, of the 15,088 establishments having firm ID change only 7,660 (50.77 percent) are identified as “acquired". The remaining 6,739 establishments (44.66 percent) changed their IDs for unknown reasons.

Before proceeding, it is important to point out that, for the periods 1963-67 and 1967-72, the numbers of plants changing firm IDs with unknown reasons are high (above 40 percent in both periods). In these two periods, because ASM data were not available before 1972, it is impossible to identify those plants that were acquired in the years between any given two census years, and those were opened after the previous census year and sold before the next census year ${ }^{11}$. Thus, for these two periods, most plants

${ }^{11}$ Indeed, the average employment for plants identified as "acquired' during the 1963-67 and 1967-72 periods are 312 and 231 employees, respectively. These figures are substantially larger than a typical U.S. manufacturing plant that employs about 50 workers. 
that were identified as having true ownership change were large ASM plants. Only a small number of small surviving plants were identified as "acquired".

For the period 1972-77, with ASM data available for the years 1973-76 it was possible to reduce the "unknown' category to 25 percent and to increase the "acquired" category to 63 percent. This increase in the number of plants identified as having true ownership change is largely attributed to the available ASM data which allow identification of additional smaller plants acquired in the years between the two censuses. Thus, the average employment of acquired plants during 1972-77 is 169 employees, which is much smaller than those in previous periods.

The proportions of acquired plants (among the universe of firm ID changes) for the periods 197782, 1982-87 and 1987-92 increase to $70.11,74.78$ and 76.73 percent, whereas the proportion of plants with "unknown" firm ID changes reduces to $12.96,13.58$ and 15.78 percent, respectively. Again, the reason for this improvement is that with ASM data available in 1973 and succeeding years, it was possible to observe $\mathrm{CC}$ codes for several years before the initial census year as well as after the ending year. Also, merger and acquisition activities in manufacturing increase during the more recent periods. ${ }^{12}$ When measuring the proportions of the categories of firm ID changes in terms of total value of shipments (TVS) and total employment (TE), we find that the proportions of the "acquired" category increase, while the "unknown' category decreases substantially (see Charts $2 \& 3$ and columns $3 \& 5$, table 4) compared to the proportions based on the number of plants (see Chart 1 and column 2 , table 4): The proportions of "acquired" TVS and TE in 1963-67 are 64.46\% and 63.46\%. The corresponding proportions in $1987-92$ are $90.04 \%$ and $87.93 \%$, respectively. In contrast, the TVS and TE proportions of the "unknown" category reduce to $34.44 \%$ and $36.43 \%$ in $1963-67$, while those in $1987-92$ reduce to

12 Nationally, the number of completed mergers and acquisitions increased from 926 in 1974 to 2,326 in 1981 and to 4,024 in 1986 (see Lichtenberg, 1992) 
$7.71 \%$ and $8.85 \%$, respectively. These results indicate that acquired plants are typically larger than plants having firm ID changes for other reasons, as can be seen in columns 4 and 6, table 1 . In the 1963-67 period, for example, the average TVS and TE of “acquired" plants are \$7,286,000 and 312 employees, while the corresponding figures for “other" plants are \$4,194,000 and 191 employees, respectively.

We now turn to a brief discussion of the "unknown" category. This group consists of plants that had firm ID changes either due to acquisitions or for other reasons, but they could not be identified directly because proper CC codes were not assigned to them. They could not be identified by matching sellers and buyers'IDs (step 3) because the new firm IDs of these plants did not previously exist in manufacturing. As can bee seen in table 3, in 1982 plant 11 had a new ID ( 555555) that did not exist in 1977. Moreover, there were no CC codes assigned to record the reason for the ID change and the firm did not own or purchase any other plant. Thus, it is difficult to determine whether this firm was taken over by an owner(s) new to manufacturing or, is it simply an ID change due to a legal reorganization. ${ }^{13}$

In the next section, we review a sample of studies that used the LRD-OCD data to demonstrate the usefulness of the database in economic research.

\section{What Do We Learn from the LRD-OCD Data So Far? ${ }^{14}$}

\section{Causes and Consequences of Mergers and Acquisitions}

Economists have long been interested in determining the causes and consequences of merger and acquisition activities. However, as mentioned earlier, the issues are not well understood. Theoretically,

\footnotetext{
${ }^{13}$ One way to identify the reason for the change in firm ID of these plants is to bring in information from outside sources. At this stage, because outside sources are not available at the Center for Economic Studies these ID changes are coded as "unknown".

${ }^{14}$ This review is by no means exhaustive. There are other studies that used the data, but are not discussed here due to the space limit. Also, currently there are a number of researchers using the database in their research.
} 
there are many possible motives for mergers, but the following two are often discussed extensively in the literature: (1) to increase market power, and (2) to increase efficiency. The first motive would lead to output reductions and increases in prices, while the second leads to lower costs of production, higher outputs and lower prices.

While there are some mergers for the purpose of market power, Mueller (1993) points out that "as a general theory of mergers the market power motive seems to be lacking." Jensen (1988) asserts that ' $[\mathrm{t}]$ akeovers do not waste credits or resources. Instead, they generate substantial gains: historically 8 percent of total value of both companies. Those value gains represent gains to economic efficiency, not redistribution of between various parties." (p. 23). He also asserts that these gains do not come from the creation of monopoly power.

In studies using financial data, Jensen (1988) found strong evidence that shareholders of acquired firms earn substantial gains. But, these are not necessarily social gains. If these gains are private and are at the expense of others such as employees, then they are not an indication of economic efficiency.

To test whether or not mergers improve efficiency, one needs "real" rather than financial data because financial gains to the shareholders of the firms involved in mergers are by no means a direct measure of economic efficiency or social gains. In contrast, productivity such as total factor productivity (TFP, defined as "real" output per unit of total inputs) has been considered by economists as the best measure of efficiency. The OCD provide micro data for the construction of such a measure. In what follows, we review some typical studies using the OCD together with the LRD to examine issues related to ownership changes.

Lichtenberg and Seigel (1992) are among the researchers who first used LRD data to study the causes and consequences of ownership changes. Their empirical work is based on a matching model that is closely related to the theory of job turnover developed by Jovanovic (1979) and used extensively in 
labor market studies. ${ }^{15}$ In applying this theory to ownership change, Lichtenberg and Siegel argue that "firms are constantly evaluating the match or fit between plant and parent" and that "the quality of the match is the major determinant of the corporate level decision to maintain or relinquish ownership of an establishment." This theory implies that (1) low productivity, an indicator of a poor match between the establishment and its management, will lead to a change in ownership and (2) a change in ownership will result in an improvement of productivity.

Lichtenberg and Seigel's empirical work is based on a panel of 20,493 plants owned by 5,700 firms for the period 1972-81, extracted from the LRD time-series file. For this sample, they identified nearly 21 percent of the 20,493 plants that experienced at least one ownership change. With these data, they found that plant TFP is negatively related to ownership change and that ownership change is positively related to TFP growth. They, therefore, concluded that ownership change is primarily motivated by lapses in efficiency (bad matches).

McGuckin and Nguyen (1995) argue that Lichtenberg and Seigel's version of the matching model is "too restrictive" because it does not recognize the importance of the demand side of the market: purchase of a plant or firm will be undertaken if the buyer (acquiring firm) places a higher value on the plant than does the seller (selling firm). However, there is no reason to believe that acquiring firms purchase only poorly performing plants. Indeed, there are many possible motives for mergers and acquisitions: monopoly power, synergies and tax incentives are potential motives of mergers that do not require purchase of low productivity plants. McGuckin and Nguyen also point out that Lichtenberg and Seigel's study is likely to be subject to sample selection bias because their sample includes mostly large

${ }^{15}$ According to this theory, heterogeneous groups of workers and employers continually engage in a matching process that improve the fit between workers and jobs. 
surviving plants. ${ }^{16}$ Consequently, their results might not be representative.

To avoid this potential sample selection bias, McGuckin and Nguyen (1995) used an unbalanced panel taken from the OCD and LRD, covering the entire population of the U.S. food manufacturing sector (SIC 20). This panel consists of 28,294 plants owned by all food producing firms operated during 1977-87. With these data they found that plants with high productivity were the most likely to experience ownership change. This result is consistent with Matsusaka's (1993) finding that corporate acquirers generally purchase good businesses (productive plants) rather than bad businesses. However, for a subset of large surviving plants, they found — consistent with Lichtenberg and Seigel — that initial productivity is inversely related with ownership change. Finally, they found that plant productivity growth is positively related to ownership change. They concluded that "gains from synergies between the buying and selling firms are the most important motive for ownership change during 1977-82 period" (p. 259). Managerial discipline and matching motives appear to be applicable only to mergers and acquisitions that involved large poorly performing plants.

\section{The Impact of Ownership Change on Labor}

Despite strong opposition from labor unions and widespread, often negative, press reports on ownership changes through mergers and acquisitions, there are few studies of the impact of ownership change on labor. The reason for this is the lack of appropriate data for empirical studies. To our knowledge, there was only one published study on this topic that used data other than those in the OCD and LRD. Brown and Medoff (1988) used a sample of mostly small firms from the state of Michigan. They found that, except for divestitures, ownership change had little impact on either employment or average wages.

Since the LRD became available to researchers, economists have conducted several empirical

${ }^{16} 82 \%$ of the plants in Lichtenberg and Seigel's sample have 250 or more employees. 
studies of the impact of ownership change on labor. Lichtenberg and Seigel (1992) used plant level data taken from the LRD to examine the effects of ownership change on wages and employment on both central offices and production establishments. They found that ownership change is associated with reduction in both wages and employment at central offices, but it has little effect at production establishments. Together with Brown and Medoff's findings, Lichtenberg and Seigel's results suggest that managers and white collar workers suffer the most after ownership change; but overall, the effects of ownership change on labor, particularly on production workers, appear to be small.

McGuckin, Nguyen and Reznek (1998) examined the effects of ownership changes on employment, wages and productivity using an unbalanced panel of more than 28,000 establishments taken from the LRD and OCD. The study covers the entire U.S. food producing industry (SIC 20). They found that (1) five to nine years after acquisition, the growth rates of wages, employment and labor productivity for typical acquired plants (as well as originally owned plants of acquiring firms) are higher than the typical plants of non-acquiring firms; (2) to a lesser extent, the typical worker in either category of plants owned by the acquiring firms also enjoyed higher growth rates of wages, employment and productivity after acquisitions; and (3) plants that changed owners show a greater likelihood of survival than those that did not. McGuckin and Nguyen (1998) extended this work to include data on the entire U.S. manufacturing sector for the same period and found similar results.

In brief, the results obtained from OCD/LRD data so far strongly reject the hypothesis that ownership changes through acquisition and corporate takeovers result in cutting wages and employment and in reducing economic efficiency. It is important to emphasize that uses of the OCD are not limited to the above issues. The OCD is a potentially valuable database that can be used to study many aspects of 
the economy where mergers and acquisitions could have a real impact. ${ }^{17}$

\section{CONCLUDING REMARK}

To conclude the paper, it is important to point out certain strengths and weaknesses of the OCD. One weakness of this data base is that it is biased toward surviving and /or large establishments. In particular, during the periods 1963-67 and 1967-72, when ASM data were not available, among the plants that changed owners, only those survived to the next census year could be identified. This is evident from the large average sizes of plants identified as "acquired" in the first two periods. With ASM data available beginning in 1974, additional plants that changed owners in the years between two censuses were identified in the later periods. However, even in these periods a large number of smaller non-ASM establishments that had ownership changes in the years between the two censuses and were closed before the second census year could not be identified. Similarly, a new non-ASM plant that was opened after the first census year, and changed owner before the next census year, were identified as a "new" plant of the acquiring firm. Thus, the OCD under-counts ownership changes and closed acquired plants, and overstates the number of acquiring firms' new plants.

Moreover, OCD covers manufacturing only. Thus, for companies that operate in both manufacturing and non-manufacturing, the database contains information only on the manufacturing portions of these companies.

Finally, the OCD does not contain information about certain types of ownership change, such as tender offers or hostile takeovers. These types of ownership changes are believed to perform differently

${ }^{17}$ As an example, these data can be used to study the impact of ownership changes on job creation and job destruction and their variation within and between firms. 
after mergers. ${ }^{18}$ We note, however, that it is possible to identify these of ownership change in the OCD by bringing in ouside information (e.g., McGuckin, Nguyen and Andrews, 1991).

In spite of the above shortcomings, the OCD data are unique and valuable. A major strength of this database is that it contains plant level data for the entire U.S. manufacturing sector over a rather long period of time (1963-92). These plant-level data allow researchers to take a close look inside the firm and to observe the contribution of each individual component of the firm before and after ownership change occurs. These data have been proven to be valuable in empirical studies such as research on causes and consequences of owner changes that involve "control" of the firm. In particular, the data have provided some convincing evidence on the effects of mergers and acquisitions on productivity, employment and wages. ${ }^{19}$ takeovers.

${ }^{18}$ For example, it is believed that takeover premium in hostile takeovers are larger than in friendly

${ }^{19}$ Future work on this database includes updating the file when new data become available and bringing in outside data files. Outside data would allow improvement of the identification of ownership change as well as the obtaining additional information about these changes -- such as whether an ownership change is a friendly or hostile takeover. 
Chart 1: Onerchip change6: 1963-92

(purent of fof plants)
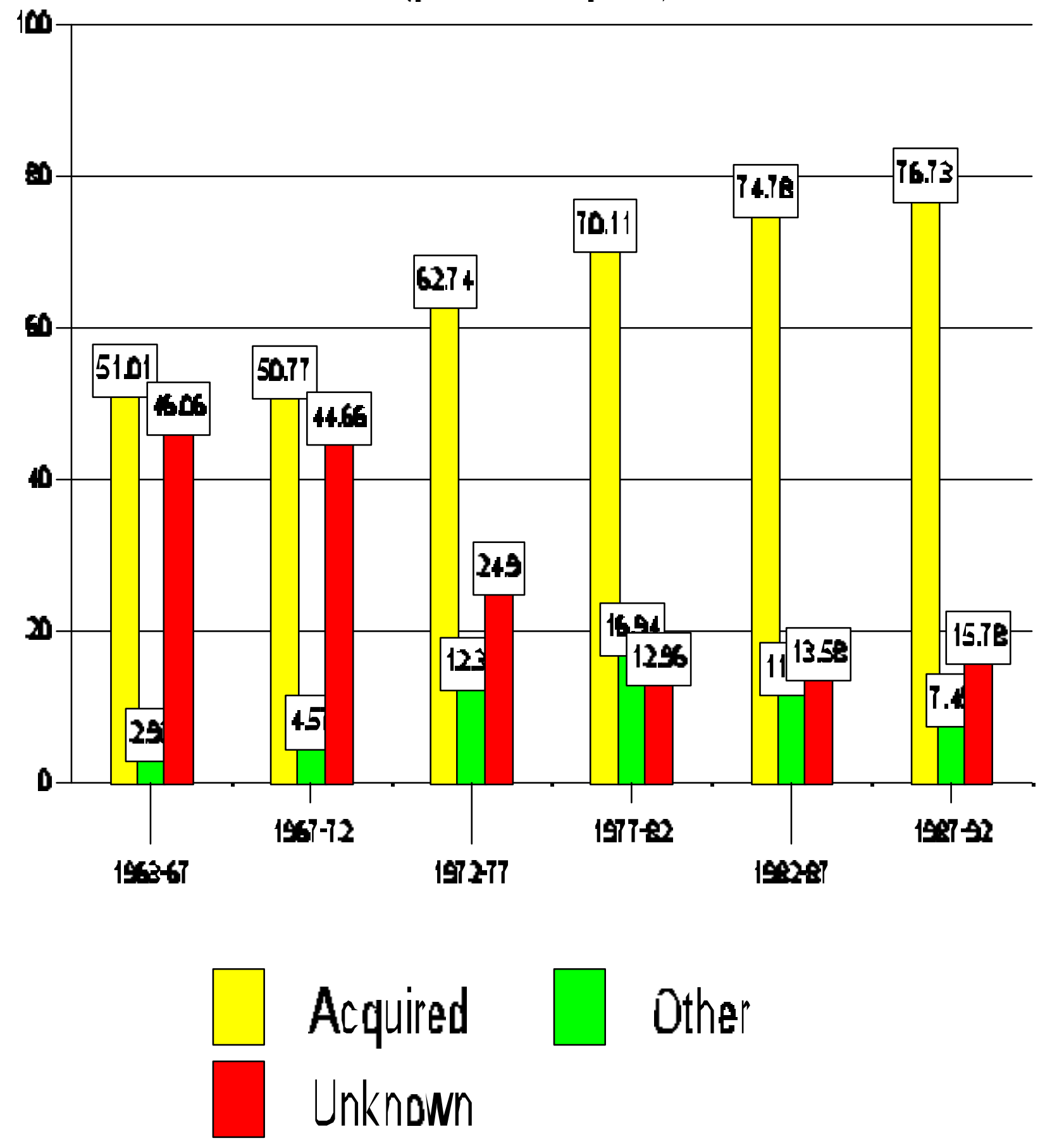


\section{Chart 2: Ownership Change: 1963-92 \\ (Percenlos boj values oistipments)}

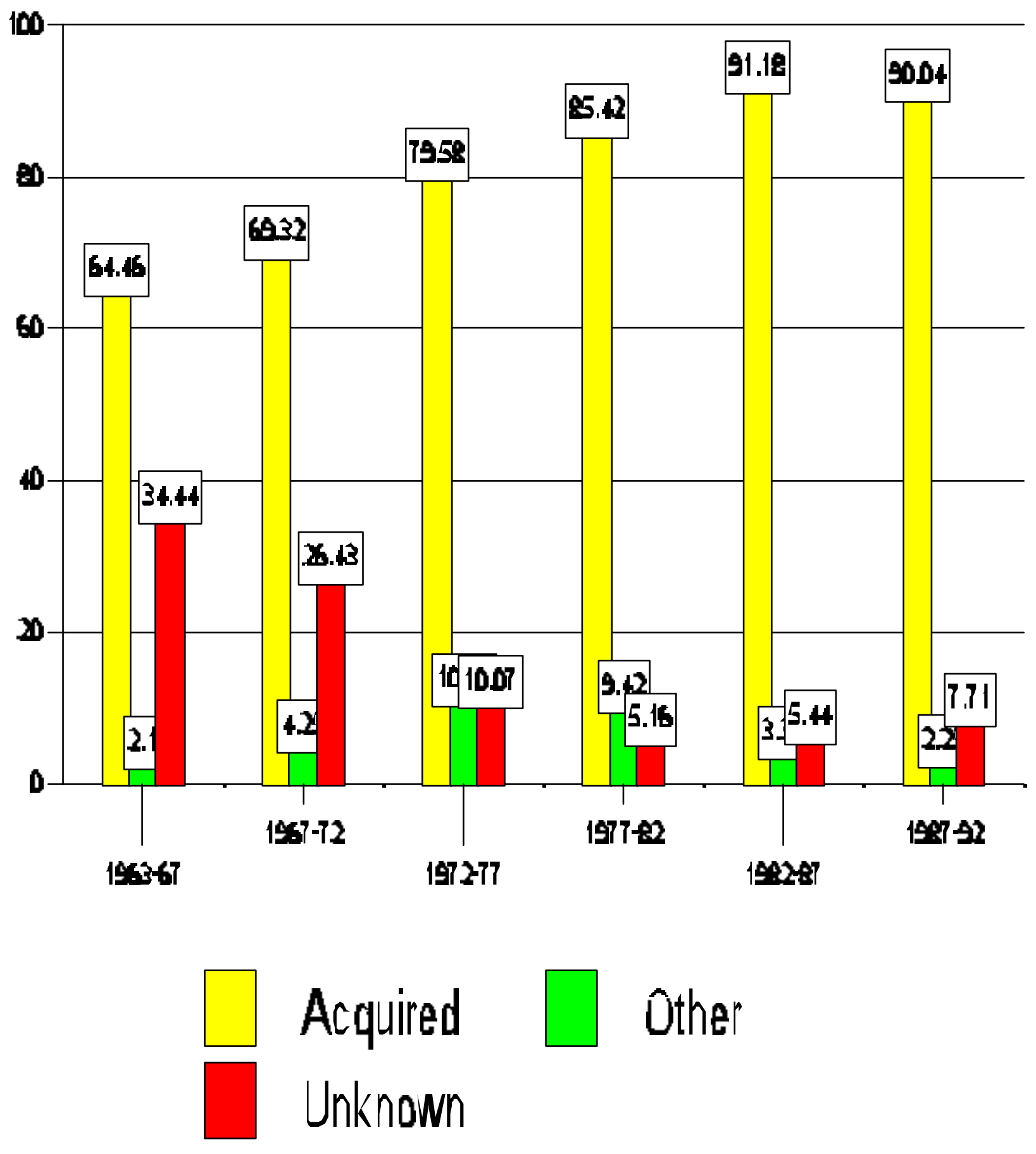


Chart 3: Identifying Ownership Change: 1963-92

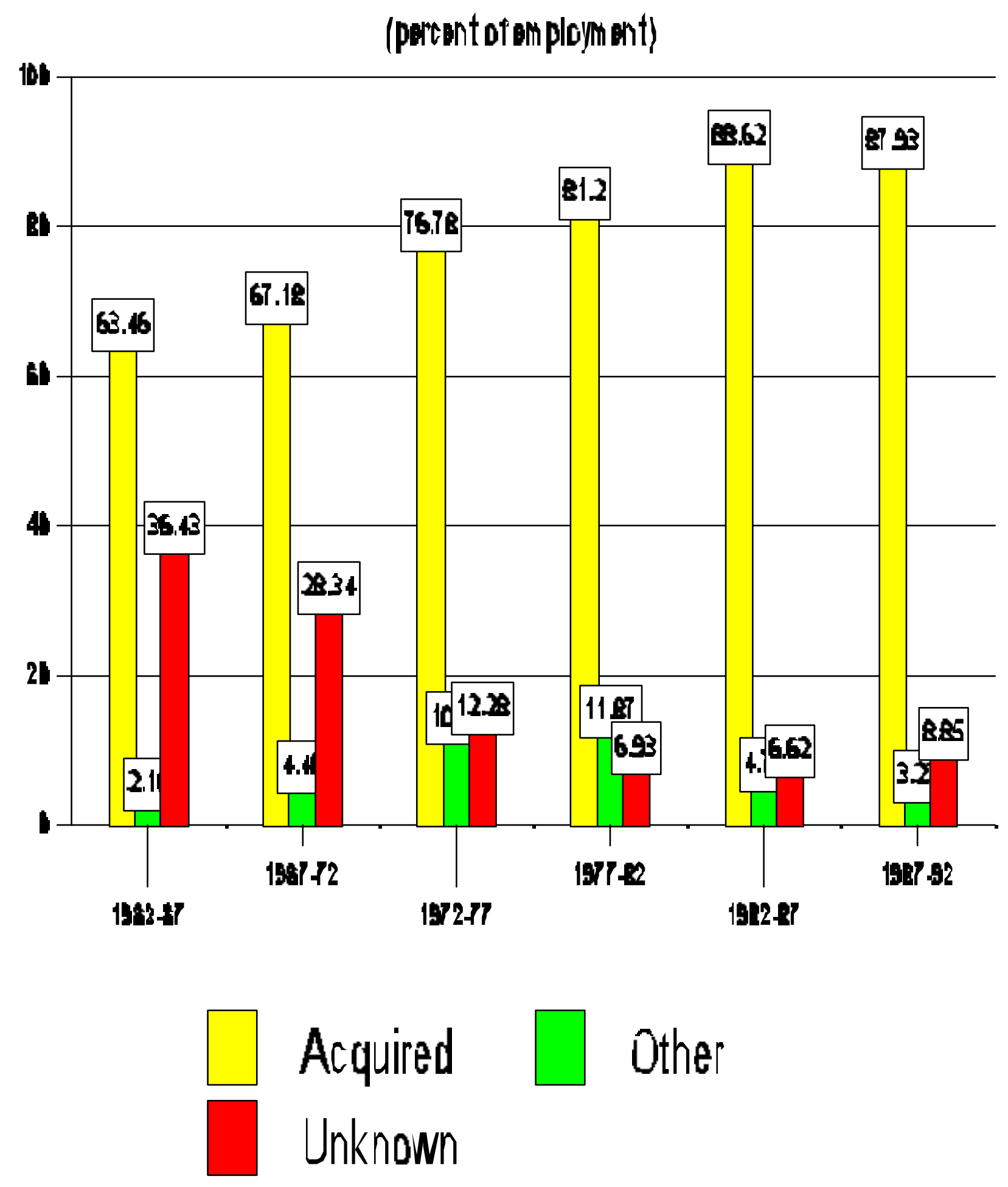


Table 1

IDENTIFYING OWNERSHIP CHANGEa

1) STEP 1: Using PPN and ID numbers to identify plants that have ID change

\begin{tabular}{lllll}
\hline $\begin{array}{l}\text { Plant } \\
\text { No. }\end{array}$ & PPN & $\begin{array}{c}1977 \\
\text { Firm ID } \\
\text { (Sellers) }\end{array}$ & $\begin{array}{c}\text { Firm ID } \\
\text { (Buyers) }\end{array}$ & $\begin{array}{c}\text { Firm } \\
\text { ID Change }\end{array}$ \\
\hline 1) & 0111110000 & $0900000000^{*}$ & 444444 & Yes \\
2) & 1111110001 & 333333 & 222222 & Yes \\
$3)$ & 1111110002 & 333333 & $0123456789 *$ & Yes \\
$4)$ & 1111110003 & 333333 & 444444 & Yes \\
$5)$ & 1111110004 & 333333 & 444444 & Yes \\
$6)$ & 1111110005 & 333333 & 222222 & Yes \\
7) & 1111110006 & 666666 & 999999 & Yes \\
$8)$ & 1111110007 & 666666 & 666666 & No \\
9) & 1111110008 & 777777 & 444444 & Yes \\
$10)$ & 1111110009 & 777777 & $0234567890 *$ & Yes \\
$11)$ & 1111110010 & 111111 & 55555 & Yes \\
\hline
\end{tabular}

* denotes single-unit firm

${ }^{a}$ All ID and PPN numbers in this table are arbitrarily made up for demonstration purposes. There are no actual numbers used in this paper. 
Table 2

IDENTIFYING OWNERSHIP CHANGE ${ }^{\mathrm{a}}$

(Continued)

2) STEP 2: Using Coverage Codes (CC) to identify reasons for firm ID change.

\begin{tabular}{|c|c|c|c|c|c|c|}
\hline $\begin{array}{l}\text { Plant } \\
\text { No. }\end{array}$ & PPN & $\begin{array}{l}1977 \\
\text { Firm ID } \\
\text { (Sellers) }\end{array}$ & $\begin{array}{l}1982 \\
\text { Firm ID } \\
\text { (Buyers) }\end{array}$ & $\begin{array}{l}\text { Firm ID } \\
\text { Change }\end{array}$ & $\begin{array}{l}\text { Reasons } \\
\text { For ID } \\
\text { Change }^{b}\end{array}$ & $\begin{array}{l}\text { Ownership } \\
\text { Change }\end{array}$ \\
\hline 1) & 0111110000 & 0900000000* & 444444 & Yes & e & $?$ \\
\hline 2) & 1111110001 & 333333 & 222222 & Yes & "Sold" & Yes \\
\hline 3) & 1111110002 & 333333 & $0123456789 *$ & Yes & “MU/SU”' & No \\
\hline 4) & 1111110003 & 333333 & 444444 & Yes & "Sold" & Yes \\
\hline 5) & 1111110004 & 333333 & 444444 & Yes & . & $?$ \\
\hline 6) & 1111110005 & 333333 & 222222 & Yes & "Sold" & Yes \\
\hline 7) & 1111110006 & 666666 & 999999 & Yes & "Error" & No \\
\hline 8) & 1111110007 & 666666 & 666666 & No & "No Change" & No \\
\hline 9) & 1111110008 & 777777 & 444444 & Yes & "Sold" & Yes \\
\hline 10) & 1111110009 & 777777 & $0234567890 *$ & * Yes & “MU/SU” & No \\
\hline 11) & 1111110010 & 111111 & 555555 & Yes & . & $?$ \\
\hline
\end{tabular}

* denotes single-unit firm.

${ }^{\text {A }}$ All ID and PPN numbers in this table are arbitrarily made up for demonstration purposes. There are no actual numbers used in this paper.

${ }^{\mathrm{B}}$ Identified by CC codes. 
Table 3

\section{IDENTIFYING OWNERSHIP CHANGE (Continued)}

\section{3) STEP 3: Matching Buyers and Sellers to further Ownership Change}

\begin{tabular}{|c|c|c|c|c|c|c|}
\hline $\begin{array}{l}\text { Plant } \\
\text { No. }\end{array}$ & PPN & $\begin{array}{l}1982 \\
\text { Firm ID } \\
\text { (Buyers) }\end{array}$ & $\begin{array}{l}1977 \\
\text { Firm ID } \\
\text { (Sellers) }\end{array}$ & $\begin{array}{l}\text { Firm ID } \\
\text { Change }\end{array}$ & $\begin{array}{l}\text { Reasons } \\
\text { For ID } \\
\text { Change }^{\mathrm{b}}\end{array}$ & $\begin{array}{l}\text { Ownership } \\
\text { Change }\end{array}$ \\
\hline 2) & 1111110001 & 222222 & 333333 & Yes & "Sold" & Yes \\
\hline 6) & 1111110005 & 222222 & 333333 & Yes & "Sold" & Yes \\
\hline 4) & 1111110003 & 444444 & 333333 & Yes & "Sold" & Yes \\
\hline 5) & 1111110004 & 444444 & 333333 & Yes & & (Yes) \\
\hline 9) & 1111110008 & 444444 & 777777 & Yes & "Sold" & Yes \\
\hline 1) & 0111110000 & 444444 & $0900000000 *$ & * Yes & . & (Yes) \\
\hline 11) & 1111110010 & 555555 & 111111 & Yes & . & $(\mathrm{U})^{\mathrm{c}}$ \\
\hline 8) & 1111110007 & 666666 & 666666 & No & "No Change" & No \\
\hline 7) & 1111110006 & 666666 & 999999 & Yes & "Error" & No \\
\hline 3) & 1111110002 & $0123456789 *$ & 333333 & Yes & "MU/SU" & No \\
\hline 10) & 1111110009 & $0234567890 *$ & 777777 & Yes & "MU/SU" & No \\
\hline
\end{tabular}


a All ID and PPN numbers in this table are arbitrarily made up for demonstration purposes. There are no actual numbers used in this paper.

B Identified by $\mathrm{CC}$ codes.

c denotes "unknown".

Table 4

ID Change by Categories

\begin{tabular}{|c|c|c|c|c|c|}
\hline $\begin{array}{c}\text { Categories } \\
\text { (1) }\end{array}$ & $\begin{array}{c}\text { Number of } \\
\text { plants } \\
\text { (2) }\end{array}$ & $\begin{array}{c}\text { Total } \\
\text { Shipments } \\
\text { (thousand \$) } \\
(3)\end{array}$ & $\begin{array}{c}\text { Average } \\
\text { Shipments } \\
\text { (thousand\$) } \\
\text { (4) }\end{array}$ & $\begin{array}{c}\text { Total } \\
\text { Employment } \\
\text { (\# workers) } \\
(5)\end{array}$ & $\begin{array}{c}\text { Average } \\
\text { Employment } \\
\text { \# workers) } \\
(6)\end{array}$ \\
\hline \multicolumn{6}{|c|}{ 1963-67 } \\
\hline $\begin{array}{c}\text { Acquired } \\
(\%) \\
\text { Other } \\
(\%) \\
\text { Unknown } \\
(\%) \\
\text { Total } \\
(\%)\end{array}$ & $\begin{array}{c}3,694 \\
(51.01) \\
212 \\
(2.93) \\
3,336 \\
(46.06) \\
7,242 \\
(100.00)\end{array}$ & $\begin{array}{c}26,913,223 \\
(64.46) \\
889,195 \\
(2.10) \\
14,606,059 \\
(34.44) \\
42,408,477 \\
(100.00)\end{array}$ & $\begin{array}{c}\text { 7,286 } \\
----- \\
4,194 \\
----- \\
4110 \\
----- \\
5,856 \\
-----\end{array}$ & $\begin{array}{c}1,151,226 \\
(63.46) \\
40,549 \\
(2.16) \\
683,035 \\
(36.43) \\
1,874,810 \\
(100.00)\end{array}$ & $\begin{array}{c}312 \\
---- \\
191 \\
---- \\
205 \\
---- \\
259 \\
-----\end{array}$ \\
\hline \multicolumn{6}{|c|}{ 1967-72 } \\
\hline $\begin{array}{c}\text { Acquired } \\
(\%) \\
\text { Other } \\
(\%) \\
\text { Unknown } \\
(\%) \\
\text { Total } \\
(\%)\end{array}$ & $\begin{array}{c}7,660 \\
(50.77) \\
689 \\
(4.57) \\
6,739 \\
(44.66) \\
15,088 \\
(100.00)\end{array}$ & $\begin{array}{c}50,008,621 \\
(69.32) \\
3,063,643 \\
(4.25) \\
19,068,472 \\
(26.43) \\
72,140,736 \\
(100.00)\end{array}$ & $\begin{array}{c}\text { 6,529 } \\
----- \\
4,447 \\
----- \\
2,830 \\
---- \\
4,781 \\
-----\end{array}$ & $\begin{array}{c}1,768,128 \\
(67.18) \\
117,910 \\
(4.48) \\
745,971 \\
(28.34) \\
2,632,009 \\
(100.00)\end{array}$ & $\begin{array}{c}231 \\
---- \\
171 \\
---- \\
110 \\
---- \\
174 \\
-----\end{array}$ \\
\hline \multicolumn{6}{|c|}{ 1972-1977 } \\
\hline
\end{tabular}




\begin{tabular}{|c|c|c|c|c|c|}
\hline Acquired & 8,229 & $54,161,059$ & 6,582 & $1,389,954$ & 169 \\
$(\%)$ & $(62.74)$ & $(79.58)$ & ---- & $(76.78)$ & ---- \\
Other & 1,621 & $7,042,182$ & 4,344 & 197,991 & 122 \\
$(\%)$ & $(12.36)$ & $(10.35)$ & ----- & $(10.94)$ & ----- \\
Unknown & 3,266 & $6,853,961$ & 2,099 & 222,389 & 68 \\
$(\%)$ & $(24.90)$ & $(10.07)$ & ---- & $(12.28)$ & ---- \\
Total & 13,116 & $68,057,202$ & 5,189 & $1,810,334$ & 138 \\
$(\%)$ & $(100.00)$ & $(100.00)$ & ----- & $(100.00)$ & ----- \\
\hline
\end{tabular}

Table 1 (continued)

ID Change by Categories

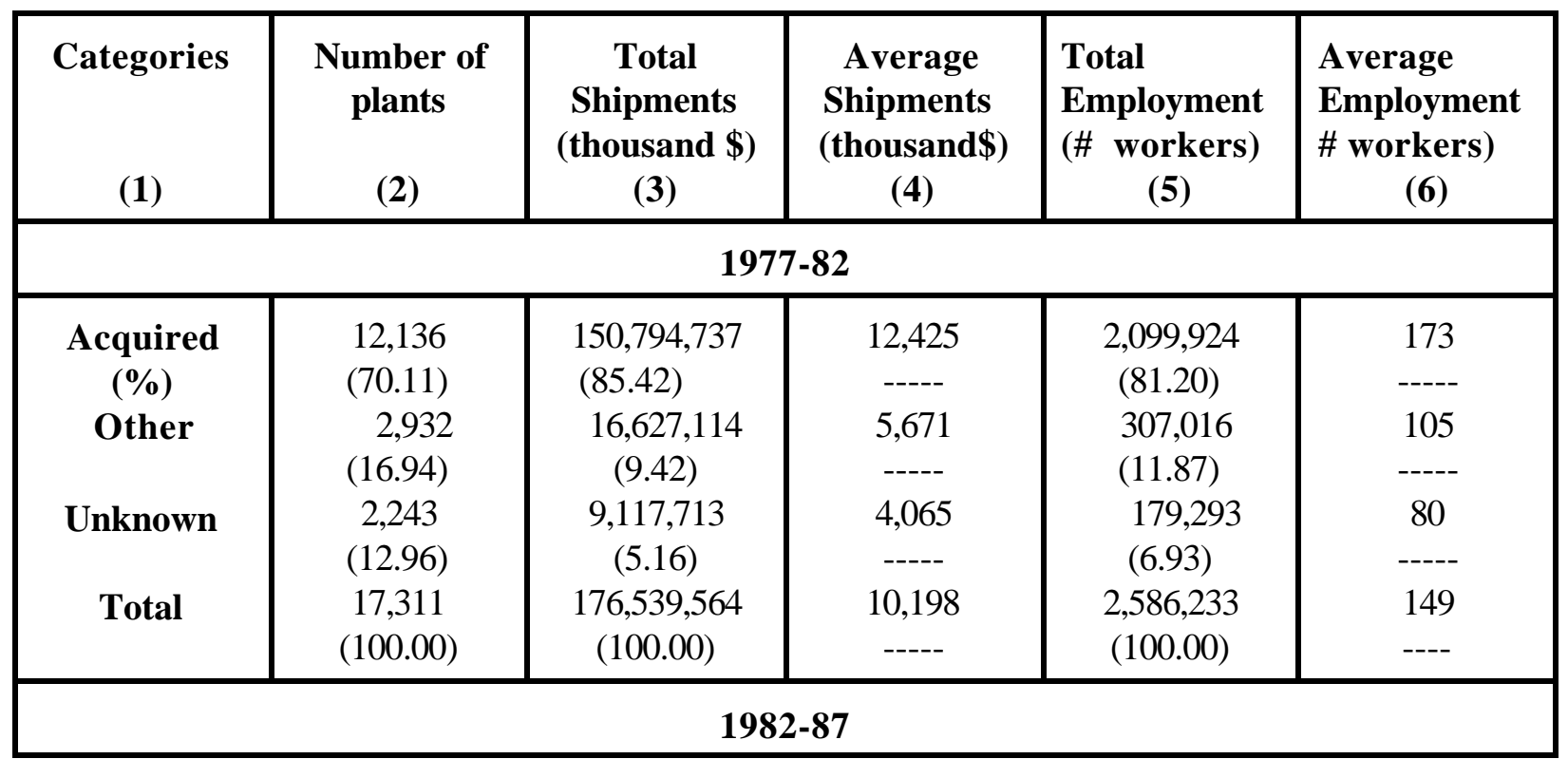




\begin{tabular}{|c|c|c|c|c|c|}
\hline $\begin{array}{c}\text { Acquired } \\
(\%) \\
\text { Other } \\
(\%) \\
\text { Unknown } \\
(\%) \\
\text { Total } \\
(\%)\end{array}$ & $\begin{array}{c}15,543 \\
(74.78) \\
2,420 \\
(11.64) \\
2,822 \\
(13.58) \\
20,785 \\
(100.00)\end{array}$ & $\begin{array}{c}338,814,545 \\
(91.18) \\
12,590,406 \\
(3.39) \\
20,203,924 \\
(5.44) \\
371,608,875 \\
(100.00)\end{array}$ & $\begin{array}{c}21,799 \\
----- \\
5,203 \\
---- \\
7,159 \\
----- \\
19,035 \\
-----\end{array}$ & $\begin{array}{c}3,053,267 \\
(88.62) \\
163,826 \\
(4.76) \\
228,239 \\
(6.62) \\
3,445,322 \\
(100.00)\end{array}$ & $\begin{array}{c}196 \\
---- \\
68 \\
-81 \\
-- \\
166\end{array}$ \\
\hline \multicolumn{6}{|c|}{ 1987-92 } \\
\hline $\begin{array}{c}\text { Acquired } \\
(\%) \\
\text { Other } \\
(\%) \\
\text { Unknown } \\
(\%) \\
\text { Total } \\
(\%)\end{array}$ & $\begin{array}{c}10,096 \\
(76.73) \\
986 \\
(7.49) \\
2,076 \\
(15.78) \\
13,158 \\
(100.00)\end{array}$ & $\begin{array}{c}286,026,773 \\
(90.04) \\
7,144,863 \\
(2.25) \\
24,498,564 \\
(7.71) \\
317,670,200 \\
(100.00)\end{array}$ & $\begin{array}{c}29,056 \\
---- \\
7,071 \\
----- \\
17,518 \\
---- \\
25,735\end{array}$ & $\begin{array}{c}1,966,736 \\
(87.93) \\
72,053 \\
(3.22) \\
197,866 \\
(8.85) \\
2,236,655 \\
(100.00)\end{array}$ & $\begin{array}{c}211 \\
--- \\
76 \\
--- \\
119 \\
--- \\
188\end{array}$ \\
\hline
\end{tabular}

\section{REFERENCES}

Berle, A. A. and G. C. Means (1932), The Modern Corporation of Private Property, New York:

Commerce Clearing House, Revised Version, New York: Harcourt, Brace and Jovanovich, 1968.

Brown, C. and Medoff, J.L. (1988), "The Impact of Firm Acquisition on Labor," in Corporate

Takeovers: Causes and Consequences, Alan J. Auerbach (ed.), Chicago and London: The

University of Chicago Press, pp. 9-25.

Cole, S. J., J. Petrick and R. E. Struble (1995), “The Relatioship between the Standard Statistical 
Establishment List and Manufacturing Establishment Surveys," U.S. Bureau of the Census, Manufacturing and Construction Division, MCD Working Paper \# Census/MCD/WP 95/02.

Healy, P., Palepu, K., and Ruback, R. (1990), “Does Corporate Performance Improve After Mergers?” NBER Working Paper, No. 3348.

Jensen, M. C. (1988), “The Takeover Controversy: Analysis and Evidence,” in J.C. Coffee, Jr., L. Lowenstein, and Rose-Ackerman (eds.), Knights, Raiders, and Targets: The Impact of Hostile Takeover: Oxford: Oxford University Press.

Jovanovic, B. (1979), "Job Matching and the Theory of Turnover," Journal of Political Economy, Vol. 87, pp. 972-990.

Kaplan, S. (1989), “The Effect of Management Buyouts on Operating Performance and Value,” Journal of Financial Economics, 24, pp. 217-54.

Lichtenberg, F.R. and Siegel, D. (1992a), "Productivity and Changes in Ownership of Manufacturing Plants," in Corporate Takeovers and Productivity, F. Lichtenberg (ed.), Cambridge: The MIT Press, pp. 25-43.

Lichtenberg, F.R. and Siegel, D. (1992b), "Takeovers and Corporate Overhead," in Corporate Takeovers and Productivity, F. Lichtenberg (ed.), Cambridge: The MIT Press, pp. 45-67.

Matsusake, J. G. (1993), “Target profits and Managerial Discipline During the Conglomerate Merger Wave," Journal of Industrial Economics, Vol. 41, pp. 179-89.

McGuckin, R.H. and Nguyen, S.V. (1995), "On Productivity and Plant Ownership Change: New Evidence from the LED," The RAND Journal of Economics, Volume 26, Number 2, pp. 257-76. McGuckin, R.H. and Nguyen, S.V. (1998), "Exploring the Role of Acquisition in the Performance of Firms: Is the "Firm" the Right Unit of Analysis?" in Micro and Macro-data, Statistical Analysis and International Comparision, Silvia Biffigadi (ed.), Italy: Phisica-Verlag (forcoming, 1998) 
McGuckin , R.H, Nguyen, S.V., and Reznek, A.P. (1998), " On Measuring the Impact of Ownership Change on Labor: Evidence from U.S. Food Manufacturing Data," in Labor Statistics Measurement Issue, John Haltiwanger, Marilyn Manser and Robert Topel (eds.), Chicago: NBER (forthcoming, 1998).

McGuckin , R.H, Nguyen, S.V. and Andrews S. H., "The Relationships Among Acquiring and Acquired Firms' product Lines," Journal of Law and Economics, Vol. XXXIV, No. 4 (October 1991):477502.

McGuckin, R.H. and Pascoe, G. (1988), "The Longitudinal Research Database: Status and Research Possibilities," Survey of Current Business, Volume 68, Number 11, pp. 30-37.

Mueller, D. C. (1993), ‘Mergers: Theory and Evidence,' in Gallium Mussati, ed., Mergers, Markets, and Public Policy, Dordrecht; Kluwer.

Revenscraft, D., and Scherer, F.(1987), Mergers, Sell-Offs, and Economic Efficiency. Washington D.C.: The Brookings Institution.

U. S. Bureau of the Census (1979) “The Standard Statistical Establishment List Program,” U. S. Department of Commerce, Washington D.C.

\section{APPENDIX}

\section{DESCRIPTIONS OF VARIABLES}

The OCD consists of 6 separate files: (1) OC6367, (2) OC6772, (3) OC7277, (4) OC7782, (5) OC8287 and (6) OC8792. Each file contains data on the following variables: 


\section{Name: $\quad$ ID of the Buying (Acquiring) Firm}

Symbol: $\quad$ BUYID

Description: For single-unit firms, BUYID is a 10-digit ID number. For multi-unit firms, it is a 6-digit firm ID number, common to all all establishments owned by that firm (see ID below).

\section{Name: $\quad$ Coverage Code}

Symbol: $\quad$ CC (e.g., CC77 = 1977 CC code)

Description: A two-digit code used to identify establishments that have had a change in their operations from the previous year. This code is used to identify whether a change in the firm ID of the plant is a true ownership change.

Note : $\quad$ The $\mathrm{CC}$ codes are also very useful for understanding administrative changes in establishments and for identifying changes in operational status of establishments. They are particularly useful when working with the ASM establishments in a panel, since most of the codes are directly related to changes in operational status of plants in the ASM. Note, the codes should be interpreted as indicating changes that are affecting the establishment in the current year (or perhaps in some cases in the prior year). The information in a $\mathrm{CC}$ code, however, does span many periods. Thus, establishments born between Census years that are not part of the ASM are not given birth codes in the first Census they appear unless they are newly opened in the Census year..

One shortcoming of the CC codes is that the information content contained in the field diminishes over time. That is, it is more likely in the 1980s and 1990s to have an establishment CC code be 0 (no change in operations) when in fact a change in operation had occurred.

Name: Identification Number

Symbol ID (e.g., ID77 = 1977 ID number)

Description: An establishment's ID is a ten-digit number assigned by the Census Bureau. This number provides information on the organizational status and company affiliation of the plant. If an establishment is part of a enterprise with additional plants in either manufacturing or other sectors (e.g., wholesale or retail trade, service industries, etc.) it is classified as a "multi-unit" (MU) establishment and its ID number consists of a six-digit company number, common to all establishments of that company, followed by a four-digit number specific to the reporting establishment. For all other establishments ("single-units") the ID is composed of a leading zero followed by the plant's nine-digit EI. (Multi-unit IDs can not begin with zero.)

Name: $\quad$ Industry Code

Symbol: $\quad$ IND (e.g., IND77 = 1977 4-digit SIC industry) 
Description: IND is the code used to assign each and every establishment to a primary Industry for tabulation purposes. The general industry coding program used at the Census Bureau assigns each establishment a particular industry code on the basis of its recorded shipment (or production) values for product categories or classes. This code is referred to as the "derived" industry code in ASM years and as the general industry code in census years. It is derived by summing all non-defective product data to industry totals and assigning the code for the industry with the largest value. (If the establishment has no product with a value greater than zero then the historic code (i.e, the prior year tabulated code for ASM cases; otherwise the stencil code or recorded SSA code) is assigned. If two or more industries tie with the largest value, the tied industry matching the establishment's historic code at the four-digit level is assigned. If no match is made at this level, the matching tied industry is assigned as the establishment's industry code. In those cases where there is either no match at any level or there are two tied industries matching the historic code at the two or three-digit level, the computer will arbitrarily assign a current industry code based on the last digit of the tied sum being odd or even.

Note: $\quad$ The IND variable in the LRD and OCD is based upon the current SIC coding scheme.

Name: $\quad$ Permanent Plant Number

Symbol: $\quad$ PPN

Description: The PPN is a ten-digit identification number that is assigned to every establishment in the LRD. It is the main establishment-level longitudinal link variable in the LRD.

Note: $\quad$ In principle, the PPN should be a time-invariant establishment-level identifier that can be used to link an establishment's records across time. It should not change when an establishment undergoes an ownership change, nor should it change when an establishment changes single-/multi-unit status, changes in legal form of ownership, or for any other change in organizational structure or administrative action. However, PPNs cand and do change in some cases:

(1) Some Census Bureau processing require that a PPN for an establishment changes (e.g., establishments are split or combined).

(2) When a multi-unit establishment becomes a single-unit establishment, the PPN. Will be reassigned based on the single-unit PPN assignment algorithm.

(3) Errors.

Name: $\quad$ ID of the Selling (Acquired) Firm

Symbol: $\quad$ SELLID

Description: For single-unit firms, SELLID is the 10-digit ID number of the plant before it is acquired. For multi-unit firms, it is a 6-digit firm ID of the selling firm.

Name: $\quad$ Status of the Plant 


\section{Symbol: $\quad$ Status}

Description: This variable indicates whether the change in the ID of a plant is an ownership change or for other reasons:

Status = "acquired": the plant was acquired by another firm.

a

Status = "combine": the plant's data are now being included with other plants'data on new combined report.

Status = "duplicat": the plant is duplicate duplicate of another plant.

Status = "eichge": company structural change (EI change) with no actual change in ownership.

Status = "error": the plant was added in error to the company or to the control file.

Status = "nonmanu": the plant is non-manufcturing or out-of-scope.

Status = "reclassi": the plant was previously classified as non-manufacturing that has now been reclassified as manufacturing as a result of census processing.

Status = "reactiva": previously idle plant that resumed activity.

Status = "reorg": legal reorganization with no change in ownership.

Status = "soldtonm": the plant is sold or leased to non-manufacturing company.

Status = "Split": new operation resulting from the splitting of a previously combined report.

Status = "unknown": the plant has firm ID change with an unknown reason.

\section{Name T otal Employment}

Symbol: $\quad$ TE (e.g., TE77 = 1977 total employment)

Availability: All establishments

Description: This vriable record the sum of the average number of production workers for the mid-month payroll periods of March, May, August and November and the number of non-production personel employed during the pay period including the $12^{\text {th }}$ of March.

Name: $\quad$ Total Value of Shipment

Symbol: $\quad$ TVS (e.g., TVS77= 1977 total value of shipment)

Availability: All years, all establishments in the OCD.

Description: TVS is reported as the sum of (1) product values (recorded in product classes (PVC) in survey (ASM) years and in product records (PV) in census years); (2) receipts from contract work performed for others (RCW); (3) sales of products bought and resold without further processing (VR); and miscellaneous receipts for installation and

repair work, sales of scrap, etc. (MSC).

The reported TVS figure is considered a more reliable figure than the sum of the individual components. If this sum does not equal the reported total, a product class or product record is imputed to bring them into balance. 